\title{
Synthesis and Photocatalytic Sterilization Performance of $\mathrm{SA} / \mathrm{TiO}_{2}$
}

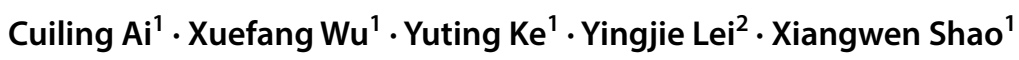

Received: 10 December 2019 / Accepted: 2 March 2020 / Published online: 23 March 2020

(c) Springer Science+Business Media, LLC, part of Springer Nature 2020

\begin{abstract}
The photocatalyst sorbic acid (SA)/titanium dioxide $\left(\mathrm{TiO}_{2}\right)$ was successfully synthesized by sol-gel method and characterized. The composite exhibited regularly spherical particles with the size of $50 \mathrm{~nm}$ and the specific surface area of $90.3 \mathrm{~m}^{2} \mathrm{~g}^{-1}$, furthermore, it showed mesoporous structure and significantly improved dispersion. SA was grafted on $\mathrm{TiO}_{2}$ surface by $-\mathrm{COOTi}$ and $\mathrm{TiO}_{2}$ existed as pure anatase phase in the composite. The addition of $\mathrm{SA}$ made the band gap of $\mathrm{TiO}_{2}$ increased from 3.03 to $3.35 \mathrm{eV}$, which indicting that the composite exhibited a strong response to the ultraviolet light. The optimum preparation parameters of the catalyst were as follows: $\mathrm{n}(\mathrm{Ti}): \mathrm{n}(\mathrm{SA})=1: 0.05$, ethanol $60 \mathrm{~mL}$, glacial acetic acid $40 \mathrm{~mL}$, hydrothermal temperature $180^{\circ} \mathrm{C}$, hydrothermal time $12 \mathrm{~h}$. The composite could reach the $4.31 \log$ reduction of $E$. coli, with the optimum catalyst dosage of $0.7 \mathrm{~g} \mathrm{~L}^{-1}$, irradiated by UV light for $60 \mathrm{~min}$. SA/TiO ${ }_{2}$ was an environmentally friendly, non-toxic and safe sterilized nanocomposite material appropriate for future bactericidal applications, providing a new way to effectively increase the dispersion of $\mathrm{TiO}_{2}$ particles to achieve superior photocatalytic sterilization efficiency.
\end{abstract}

Keywords In situ modification $\cdot$ Sorbic acid $\cdot \mathrm{TiO}_{2} \cdot$ E. coli $\cdot$ Sterilization activity

\section{Introduction}

With the rapidly increasing of living conditions, highly attention has been paid to how to keep healthy, and microbial contamination has gradually been a serious problem plaguing human beings. Many different kinds of bacteria can result in people's illness and even death. According to the World Health Organization (WHO), there are more than 2.1 billion people lack safe drinking water [1], provoking people to seek sterilization materials to settle this problem. Up to now, various antibiotics, metabolic inhibitors and bactericides have been employed to kill bacteria. However, it is found that the widely uses of sterilization materials will bring about some tricky problems, including producing the antibiotic-resistant bacteria and leading to environmental pollution, greatly limiting their applications. Therefore, an effective and new sterilization material is still required.

Cuiling Ai

aicuiling@163.com

1 College of Civil Engineering, Fuzhou University, Fuzhou 350108, Fujian, China

2 Department of Chemistry \& Chemical Engineering, Tianjin University of Technology, Tianjin 300384, China
Since $\mathrm{TiO}_{2}$ was firstly reported having excellent sterilization effect under UV radiation by Matsunaga et al. [2], it had received increasing attention. Moreover, $\mathrm{TiO}_{2}$ itself had advantageous properties including safety, insoluble in water and highly chemical stability [3], which implied it was an excellent choice for water treatment. Further researches were conducted to explore its photocatalytic sterilization activity and mechanism, and $\mathrm{TiO}_{2}$ was verified that it could transfer toxic and non-biodegradable organic pollutants into small molecules such as water and carbon dioxide by photocatalytic oxidation [4]. It was notable that many researches manifested $\mathrm{TiO}_{2}$ also had superior sterilization performance against many bacteria, including Staphylococcus aureus, Aspergillus niger, Bacillus atrophaeus, Giardia lamblia and etc. [5]. For instance, the sterilization efficiency of $\mathrm{TiO}_{2}$ for Staphylococcus aureus could reach 93\% irradiated by UV light for $30 \mathrm{~min}$ [6], while its was up to $97 \%$ for Giardia lamblia under UV light irradiation for an hour [7], showing that $\mathrm{TiO}_{2}$ possessed broad and efficiency sterilization activity, which was beneficial to apply in actual drinking water treatment to deal with different bacteria.

With so many superior advantages described above, $\mathrm{TiO}_{2}$ was considered as an excellent potential material to deal with microbial contamination problems. However, there was a big obstacle in actual application which the 
surface area, free energy and binding energy of the $\mathrm{TiO}_{2}$ catalyst substantially increasing when the crystal size decreasing, making the catalyst agglomerate and eventually leading to the unsatisfied photocatalytic effect [8]. Therefore, the dispersion of $\mathrm{TiO}_{2}$ was expected to overcome. It was reported that the element doping [9], noble metal loading [10], semiconductor compounding [11] and surface modification by organic compounds were useful to tackle this problem [12]. Especially, the surface modification of $\mathrm{TiO}_{2}$ enhancing its surface acidity, was a feasible way to improve its photocatalytic activity. The reason was that the concentration of $\mathrm{Ti}^{3+}$ and the adsorption concentration of $\mathrm{O}^{2-}, \mathrm{O}^{-}$on the $\mathrm{TiO}_{2}$ surface would reduce, while the oxygen defect sites would increase after modified by acid [13]. As a result, it could effectively hinder the electron-hole recombination and improve $\mathrm{TiO}_{2}$ photocatalytic activity. It was obvious that modification by strong acid greatly improved $\mathrm{TiO}_{2}$ photocatalytic activity, for example, the photocatalytic activity of $\mathrm{SO}_{4}{ }^{2-} / \mathrm{TiO}_{2}$ was $2-10$ times higher than that of $\mathrm{TiO}_{2}$ at the same reaction conditions [14]. Nevertheless, $\mathrm{TiO}_{2}$ modified by strong acid was unsuitable to apply in drinking water treatment due to its high toxicity and researchers turned to try using weak acid to modify it. Compared with the pure $\mathrm{TiO}_{2}, \mathrm{TiO}_{2}$ modified by surfactants oleic acid had higher photocatalytic activity and could degrade methylene blue efficiently even at low concentration [12]. Besides, the $\mathrm{TiO}_{2}$-stabilized Pickering emulsion, which was successfully modified by salicylic acid, provided a new way to the degradation of insoluble organic pollutants [15]. These results indicated that weak acid could also effectively modify $\mathrm{TiO}_{2}$ to increase its photocatalytic activity. Hence, the surface modification by the lower nontoxic weak acid was probably a feasible way to increase the photocatalytic sterilization activity of $\mathrm{TiO}_{2}$, which was suitable to apply in water treatment.

As an internationally recognized food preservative, sorbic acid was a safe and reliable food additive and it could convert into water and carbon dioxide without accumulating in human bodies, which was less toxic than salt [16]. Many experiments indicated that sorbic acid inhibited the growth of microorganisms by affecting their dehydrogenase reproduction system [17]. The antiseptic effect of sorbic acid could reach 5-10 times as good as that of benzoate, which would effectively inhibit the reproduction of clostridium bacillus, fungi and yeasts, moreover, considering its $\mathrm{C}=\mathrm{C}$ bonds, it having high chemical reaction activity, easy to have formation, halogenation, hydrogenation, oxidation, esterification, decarboxylation reaction and etc. [18]. Remarkably, SA was successfully employed in improving the dispersion performance of styrene-butadiene rubber (SBR)/halloysite nanotubes (HNTs) nanocomposites by direct blending [19] and thus SA was chosen to modify $\mathrm{TiO}_{2}$ attempting to increase its dispersion, too.
In this paper, the $\mathrm{SA} / \mathrm{TiO}_{2}$ was successful synthesized by a sol-gel method and different characterization methods were used to analyze the characterization of surface modification. The photocatalytic sterilization activity of the samples was evaluated by using $E$. coli as target bacteria and $\log$ reduction as the evaluation index. The optimum process parameters and the influence of different factors on the sterilization effect were systematically investigated. In short, this work provided a new way to effectively increase the photocatalytic sterilization activity of $\mathrm{TiO}_{2}$ by SA modification.

\section{Experimental}

\subsection{Materials}

Sorbic acid $\left(\mathrm{C}_{6} \mathrm{H}_{8} \mathrm{O}_{2}\right)$ and tetrabutyl titanate $\left(\mathrm{C}_{16} \mathrm{H}_{36} \mathrm{O}_{4} \mathrm{Ti}\right)$ were purchased from Aladdin Reagent Co, Ltd. Ethanol $\left(\mathrm{C}_{2} \mathrm{H}_{6} \mathrm{O}\right)$, acetic acid $\left(\mathrm{C}_{2} \mathrm{H}_{4} \mathrm{O}_{2}\right)$ and sulfuric acid $\left(\mathrm{H}_{2} \mathrm{SO}_{4}\right.$, $\geq 98 \%$ ) were obtained from Sinopharm Chemical Reagent Co. Ltd. All chemicals were of analytical grade and were used as received without any further purification.

\subsection{Preparation of $\mathrm{SA} / \mathrm{TiO}_{2}$}

The photocatalyst of $\mathrm{SA} / \mathrm{TiO}_{2}$ was in situ fabricated using sol-gel hydrothermal method. $0.165 \mathrm{~g}$ sorbic acid was sufficiently dissolved in $60 \mathrm{~mL}$ absolute ethanol, and then dripped in $10 \mathrm{~mL}$ tetrabutyl titanate. The homogeneous yellowish solution A was obtained after magnetic stirring the mixture for $30 \mathrm{~min}$. The solution B was prepared by adding $1 \mathrm{~mL}$ concentrated sulfuric acid into $40 \mathrm{~mL}$ glacial acetic acid. Afterwards, the solution B was slowly added into solution A with intensely stirring for $30 \mathrm{~min}$, and then magnetically stirred in a constant-temperature magnetic stirrer at 60 ${ }^{\circ} \mathrm{C}$ for $5 \mathrm{~h}$. After that, the mixed resolution was poured into a Teflon autoclave and reacted at $180{ }^{\circ} \mathrm{C}$ for $12 \mathrm{~h}$, and then centrifuged with high speed to remove the supernatant. The resultant composites were washed for five times with ethanol and distilled water. Finally, $\mathrm{SA} / \mathrm{TiO}_{2}$ was obtained by drying the washed products in a drier at $60{ }^{\circ} \mathrm{C}$ for $24 \mathrm{~h}$.

\subsection{Characterization of Catalysts}

The samples were analyzed for their phase constitutions and crystal size with X-ray diffraction (XRD) (X'pert 3 and Empyrean $\mathrm{X}$-ray diffractometer, Holland) using $\mathrm{Cu}$ $\mathrm{K} \alpha$ radiation $(\lambda=0.178901 \mathrm{~nm})$ operating at $40 \mathrm{kV}$ and $30 \mathrm{~mA}$ for the angle of diffraction $2 \theta^{\circ}=5^{\circ}-80^{\circ}$ at a scanning rate of $0.02 \mathrm{~s}^{-1}$. The crystal size was calculated from $\mathrm{X}$-ray line broadening analysis by Scherrer formula. IR spectra of the samples were recorded with a Nikkoli 5700 Fourier-transform infrared (FTIR) spectrometer in the 
range of $4000-400 \mathrm{~cm}^{-1}$. The X-ray photoelectron spectroscopy (XPS) spectra of the samples were collected on an ESCALAB250 X-ray photoelectron spectrometer of Thermo Scientific (the United States). The surface morphology of the samples was found by field emission scanning electron microscopy (FE-SEM, Nova NanoSEM 230, FEI, the United States). Light absorption spectra were recorded by UV-Vis diffuse reflectance spectrum over the range of $200-800 \mathrm{~nm}$. The Brunauer-Emmett-Teller (BET) surface areas of the samples were determined by nitrogen adsorption-desorption isotherms measured on an ASAP 2460 analyzer.

\subsection{Sterilization Tests}

The Gram-negative E. coli, used as target bacteria, was incubated in a liquid medium at $37^{\circ} \mathrm{C}$ and $100 \mathrm{rpm}$ for $16 \mathrm{~h}$ to form bacteria suspensions. Then bacterial cells were collected by centrifugation (5000 rps for $10 \mathrm{~min}$ ) and re-suspended in $0.9 \%(\mathrm{w} / \mathrm{V})$ saline solution. The bacteria concentration was $10^{7}$ colony forming units per $\mathrm{mL}$ $\left(\mathrm{CFU} \mathrm{mL} \mathrm{m}^{-1}\right.$ ), which was adjusted by tenfold gradient dilution using $0.9 \%$ saline solution. Firstly, $4.5 \mathrm{~mL}$ saline solution was added into $0.5 \mathrm{~mL}$ bacteria suspensions, and then the 10 times diluted bacterial suspension was acquired under stirring. After that, taking $0.5 \mathrm{~mL}$ forming mixture in a beaker and $4.5 \mathrm{~mL}$ saline solution was added into the beaker to form new mixture by stirring. The mixture was diluted 10 times in the same process, and five kinds of bacterial solutions with dilutions of $10,10^{2}, 10^{3}, 10^{4}$ and $10^{5}$ times were prepared, respectively.

The sterilization tests procedure was described as follows: the as-prepared composite $\left(0.1 \mathrm{~g} \mathrm{~L}^{-1}\right)$ was added in a $100 \mathrm{~mL}$ beaker containing $30 \mathrm{~mL}$ of bacteria suspensions whose initial bacteria concentration was $10^{7} \mathrm{CFU} \mathrm{mL} \mathrm{m}^{-1}$, and then the bacteria and composite were mixed on a stirrer and simultaneously were irradiated by $8 \mathrm{~W}$ ultraviolet lamp for $60 \mathrm{~min}$. Afterwards, $0.5 \mathrm{~mL}$ composite-bacterial mixture were taken out and immediately diluted with a $0.9 \%$ sterile saline solution for 10 series. Composite-bacterial solutions $(0.1 \mathrm{~mL})$ with different dilution multiple were spread on agar plates. The plates were then incubated in static conditions at $37{ }^{\circ} \mathrm{C}$ for $24 \mathrm{~h}$ in an incubator. After the incubation, the number of viable bacteria colonies forming was counted by visual inspection. The corresponding control groups in the absence of the composite, including the dark control and the light control, were carried out simultaneously for the purpose of mutual comparison. All the experiments were performed in triplicates and the mean colonies number of them was calculated as the final experimental data.

\section{Results and Discussion}

\subsection{Characterizations of the Composite}

To investigate the crystal structure of the prepared composite, the XRD patterns of $\mathrm{TiO}_{2}$ and $\mathrm{SA} / \mathrm{TiO}_{2}$ were measured. As shown in Fig. 1a, the characteristic peaks of the anatase $\mathrm{TiO}_{2}$ were observed at $2 \theta$ of $25.3^{\circ}, 37.9^{\circ}, 48.0^{\circ}$, $54.0^{\circ}, 55.1^{\circ}, 62.8^{\circ}, 69.0^{\circ}, 70.2^{\circ}, 75.2^{\circ}$, corresponding to the planes of (101), (004), (200), (105), (211), (204), (116), (220) and (215), respectively. There was a $2 \theta$ characteristic peak obtained at $27.5^{\circ}$ corresponding to the (110) crystal plane of the rutile $\mathrm{TiO}_{2}$, indicating that $\mathrm{TiO}_{2}$ was composed by anatase phase and rutile phase. $\mathrm{SA} / \mathrm{TiO}_{2}$ presented the same anatase phase diffraction peaks while the rutile phase diffraction peak disappeared in comparison with pure $\mathrm{TiO}_{2}$. It was because the solvothermal reaction temperature was operated below $250{ }^{\circ} \mathrm{C}$ to avoid the decomposition of SA and it was far from meeting the formation condition of rutile phase $\left(465-1000{ }^{\circ} \mathrm{C}\right)$ making the peak at $27.5^{\circ}$ disappear [20]. Therefore, $\mathrm{TiO}_{2}$ in the composite was totally composed by anatase phase.

The microscopical characteristics of $\mathrm{TiO}_{2}$ and the composite with different SA dosages were obtained by scanning electron microscopy shown in Fig. 2. It was found that the flake $\mathrm{TiO}_{2}$ obviously agglomerated with large particle size, while the composite presented spheroidal with smaller size and larger dispersion. The SEM images confirmed that the addition of SA would reduce the composite size and increase its dispersion. Moreover, shown in the images of $(c, d)$ and $(\mathrm{e}, \mathrm{f})$, the composite became lager when the molar ratio of $\mathrm{TiO}_{2}$ to $\mathrm{SA}$ was 1:0.05, however, when the molar ratio reached to 1:0.1, the composite size became too large. It showed that adding SA properly was effective to hinder $\mathrm{TiO}_{2}$ particles agglomeration, but excessive SA would coat on the $\mathrm{TiO}_{2}$ surface making the composite size become larger [21].

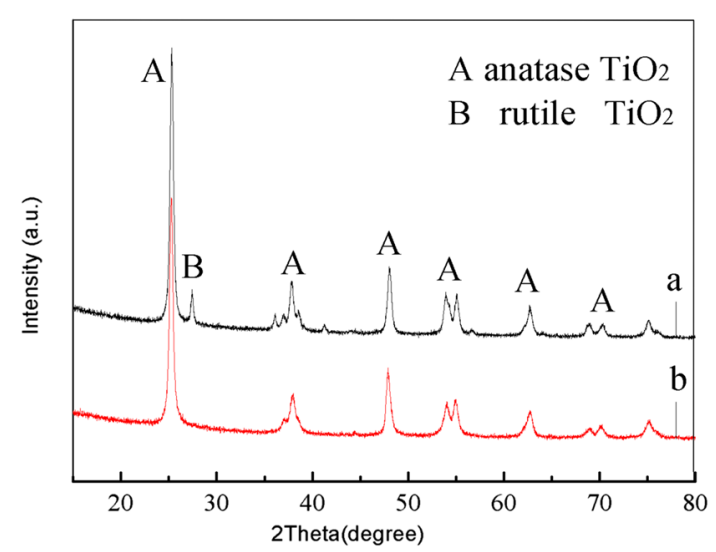

Fig. 1 XRD pattern of samples $\left[\mathrm{TiO}_{2}(\mathbf{a}), \mathrm{SA} / \mathrm{TiO}_{2}(\mathbf{b})\right]$ 

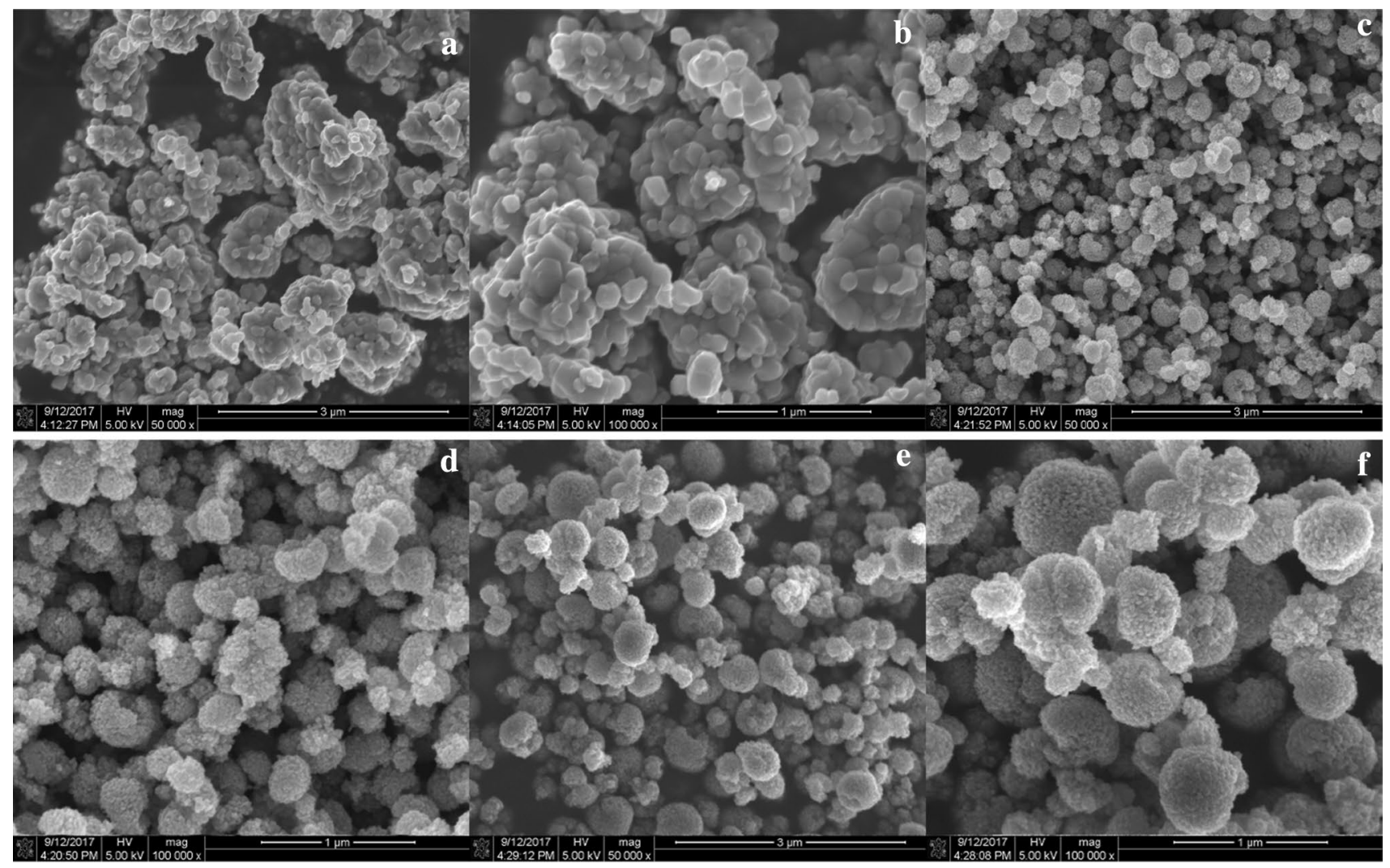

Fig. 2 SEM images of $\mathrm{TiO}_{2}(\mathbf{a}, \mathbf{b}), \mathrm{n}\left(\mathrm{TiO}_{2}\right): \mathrm{n}(\mathrm{SA})=1: 0.05(\mathbf{c}, \mathbf{d})$ and $\mathrm{n}\left(\mathrm{TiO}_{2}\right): \mathrm{n}(\mathrm{SA})=1: 0.1(\mathbf{e}, \mathbf{f})$

FT-IR spectra of $\mathrm{TiO}_{2}$, SA and $\mathrm{SA} / \mathrm{TiO}_{2}$ samples were shown in Fig. 3. The strong absorption peaks of $\mathrm{TiO}_{2}$ were obtained at 3430, 1634 and $1430 \mathrm{~cm}^{-1}$ in Fig. 3a, the first two absorption peaks resulted from the - $\mathrm{OH}$ stretching and bending modes for the absorbed water on $\mathrm{TiO}_{2}$ surface, while the last peak was ascribed to $\mathrm{Ti}-\mathrm{OH}$ after $\mathrm{TiO}_{2}$ contacted with water. SA showed strong absorption bands at $1710,1640,1612$ and $1414 \mathrm{~cm}^{-1}$ in Fig. 3b, the first two were attributed to the stretching vibration of $\mathrm{C}=\mathrm{C}$ and $\mathrm{C}=\mathrm{O}$, while the others were corresponded to the asymmetric vibration peak and symmetrical vibration peak of $\mathrm{COO}-$, respectively. Other absorption bands of SA was obtained at 3026 and $2970 \mathrm{~cm}^{-1}$ assigned to $=\mathrm{C}-\mathrm{H}$ and $-\mathrm{CH}_{3}$. For SA/TiO the new peaks at 1560,1401 and $1120 \mathrm{~cm}^{-1}$ appeared in Fig. 3c, the first two were correspond to the peak shift of the -COOTi stretching vibration absorption, implying that
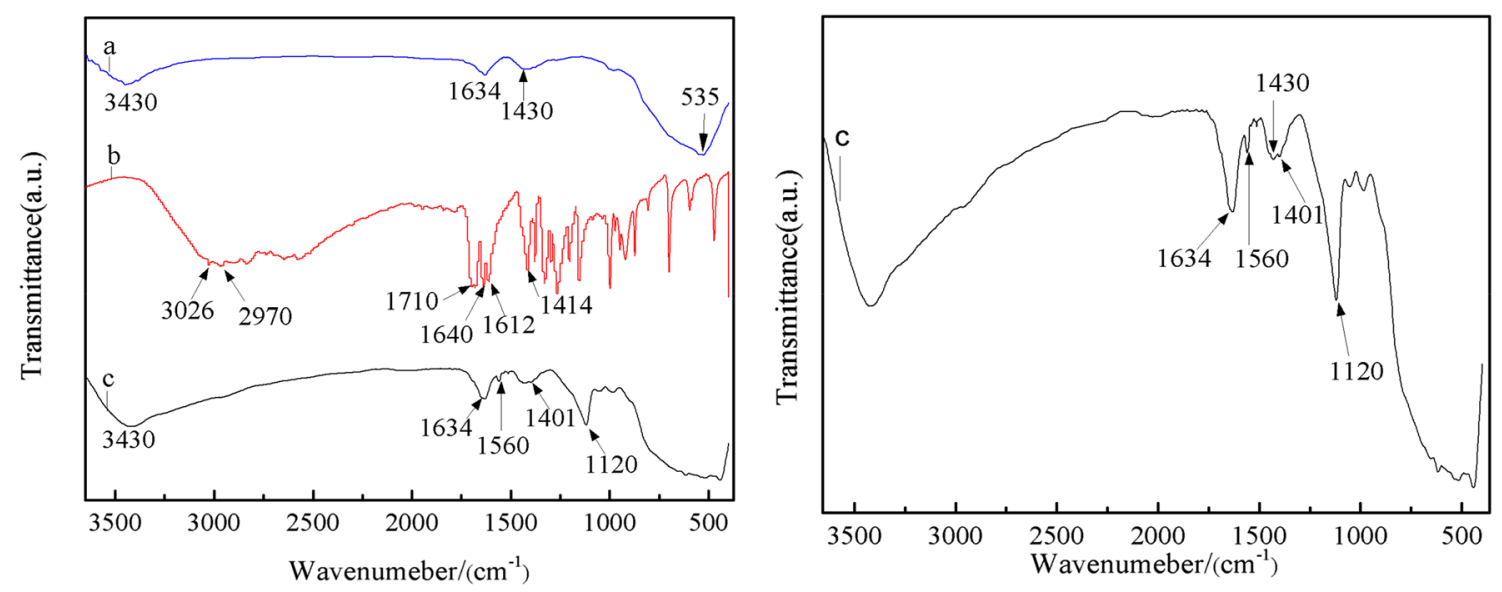

Fig. 3 FT-IR spectra of $\mathrm{TiO}_{2}(\mathbf{a})$, Sorbic acid (b) and $\mathrm{SA} / \mathrm{TiO}_{2}(\mathbf{c})$ 
SA was successfully grafted on $\mathrm{TiO}_{2}$ surface, and the emergence of new peak at $1120 \mathrm{~cm}^{-1}$ was due to the more unbalanced force between the $\mathrm{C}$ atom and the two $\mathrm{O}$ atoms in $\mathrm{SA}$ after the carboxyl combination with $\mathrm{Ti}$ atom, resulting in the double bond of $\mathrm{C}=\mathrm{O}$ broken and forming $\mathrm{C}-\mathrm{O}$ bonds. Besides, the absorption band of the composite at $1634 \mathrm{~cm}^{-1}$ was sharp assigned to the $\mathrm{C}=\mathrm{C}$ bonds from two different sources, including the original $\mathrm{C}=\mathrm{C}$ bonds in $\mathrm{SA}$ itself and the broken of $\mathrm{C}=\mathrm{O}$ bond to form new $\mathrm{C}=\mathrm{C}$ bond in $\mathrm{SA}$ [22].

The XPS spectra were applied to confirm the chemical compositions and identify the chemical bonds of the composite. It turned out that the composite was completely composed of Ti, O and $\mathrm{C}$ (Fig. 4a), which were related to $\mathrm{Ti}$ 2p, O 1s and C 1s states. As shown in Fig. 4b, the binding energy peak at $285.50 \mathrm{eV}$ and $288.44 \mathrm{eV}$ were corresponded to $\mathrm{C}-\mathrm{O}-\mathrm{R}$ and $\mathrm{O}-\mathrm{C}=\mathrm{O}$, respectively, the former originated from the composite and the latter was from SA. Ti-C was not observed at $281 \mathrm{eV}$, indicating that the $\mathrm{C}$ atoms of SA did not dope into $\mathrm{TiO}_{2}$ lattice. The $\mathrm{O}$ 1s XPS spectra Fig. 4c of the composite showed three peaks at 529.96, 531.25 and $532.66 \mathrm{eV}$, representing the oxygen atom of $\mathrm{Ti}-\mathrm{O}-\mathrm{Ti}$ in $\mathrm{TiO}_{2}$ lattice, $\mathrm{O}=\mathrm{C}$ bonds in $\mathrm{SA}$ and the hydroxyl group on $\mathrm{TiO}_{2}$ surface after it contacted with water, respectively. The Ti $2 p$ XPS spectrum had two distinct peaks at $464.1 \mathrm{eV}$ and $458.57 \mathrm{eV}$ in Fig. 4d, corresponding to the binding energies
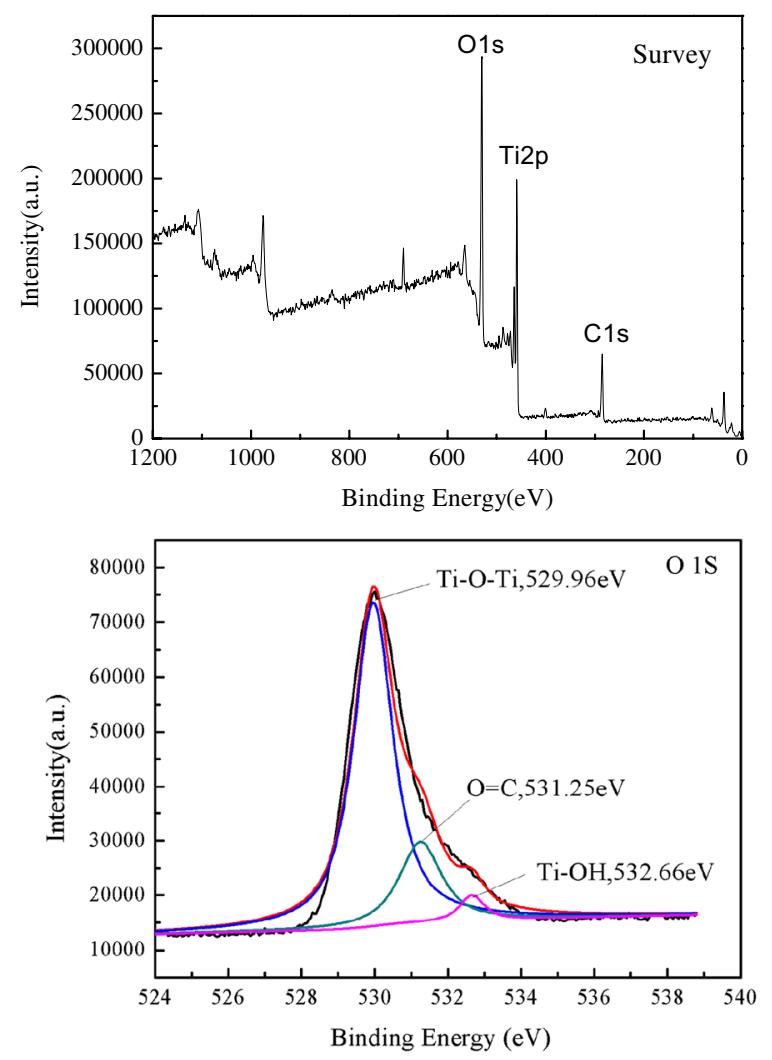

of $\mathrm{Ti}^{4+} 2 \mathrm{p}_{1 / 2}$ and $\mathrm{Ti}^{4+} 2 \mathrm{p}_{3 / 2}$, respectively, manifesting that the crystal was totally composed by $\mathrm{Ti}^{4+}$.

To understand the optical properties of the samples, the UV-Visible diffuse reflectance spectra (UV-Vis DRS) were conducted (Fig. 5). It was found that $\mathrm{TiO}_{2}$ strongly absorbed UV light with an absorption edge at $390 \mathrm{~nm}$, while the composite slightly shifted towards $370 \mathrm{~nm}$. The band gap of $\mathrm{TiO}_{2}$ and $\mathrm{SA} / \mathrm{TiO}_{2}$ was corresponded to $3.03 \mathrm{eV}$ and $3.35 \mathrm{eV}$, respectively. With the increasing of band gap, the

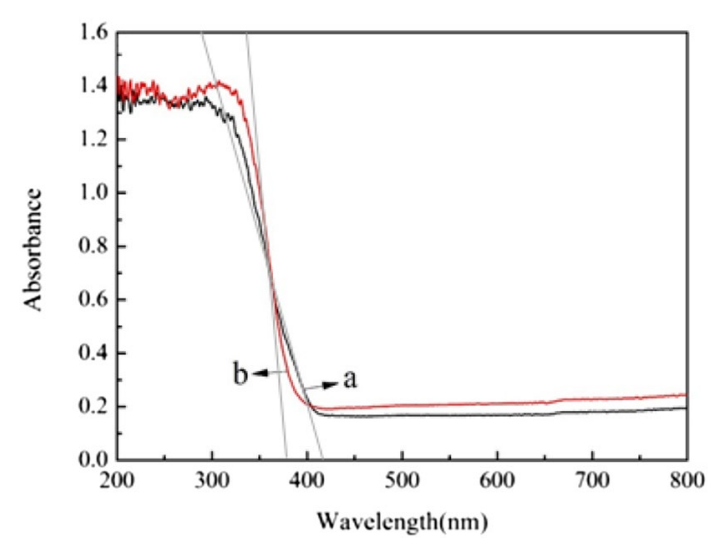

Fig. 5 UV-Vis spectra of $\mathrm{TiO}_{2}(\mathbf{a})$ and $\mathrm{SA} / \mathrm{TiO}_{2}(\mathbf{b})$
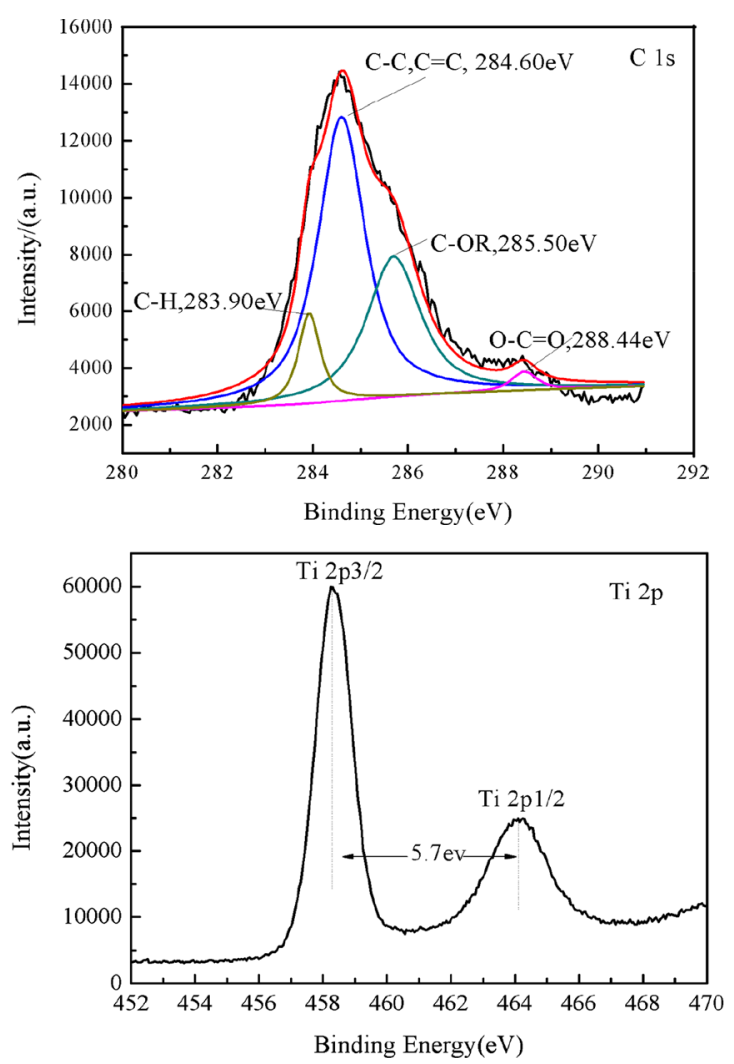

Fig. 4 XPS spectrum of SA/TiO 2 , (a) survey, b O 1s, c C 1s, and d Ti 2p 
composite had a better response to the ultraviolet light, helpful to enhance its photocatalytic efficiency.

The specific surface area of $\mathrm{SA} / \mathrm{TiO}_{2}$ was measured by $\mathrm{N}_{2}$ adsorption-desorption measurements, and the obtained isotherms was shown in Fig. 6. The sharp decline in the desorption curve and the hysteresis loop at high relative pressure clearly indicated that $\mathrm{SA} / \mathrm{TiO}_{2}$ was mesoporous structure following a representative type-IV curves with an apparent $\mathrm{H}_{3}$ hysteresis loop at relative pressure $\mathrm{P} / \mathrm{P}_{0}=0.8-1.0$, and the specific surface area of $\mathrm{SA} / \mathrm{TiO}_{2}$ was calculated to be $90.3 \mathrm{~m}^{2} \mathrm{~g}^{-1}$. The composite exhibited relatively high surface areas with more reactive surface sites compared to pure $\mathrm{TiO}_{2}$ $\left(50 \mathrm{~m}^{2} \mathrm{~g}^{-1}\right)$, suggesting that the composite was superior to adsorb bacteria to its surface.

\subsection{Determination of Preparing Process Parameters}

\subsubsection{Effect of SA-Doped Content}

The sterilization performance of $\mathrm{SA} / \mathrm{TiO}_{2}$ (the molar ratio of Ti and SA being 1:0.01, 1:0.03, 1:0.05, 1:0.1, 1:0.15, respectively) were evaluated by using $E$. coli as the target bacteria and $\log$ reduction as the evaluation index (log reduction $=\log \mathrm{A} / \mathrm{B}$, where $\mathrm{A}$ stood for bacteria colonies without the addition of the composite, and $\mathrm{B}$ stood for the number of survival bacteria colonies after disinfection process). The sterilization results of $E$. coli exposed to the as-prepared samples following $60 \mathrm{~min}$ treatment in a reactor containing the composite of $0.1 \mathrm{~g} \mathrm{~L}^{-1}$ under UV irradiation was shown in Fig. 7. It was found that the sterilization efficiency of SA/ $\mathrm{TiO}_{2}$ increased with the increasing of the molar ratio of SA adding from 0.01 to 0.05 , while the further increasing the molar ratio of SA to 0.15 , the sterilization activity of SA/ $\mathrm{TiO}_{2}$ decreased, indicating one of the best sterilization activity parameters was $n(\mathrm{Ti}): \mathrm{n}(\mathrm{SA})=1: 0.05$. The reason was that $\mathrm{TiO}_{2}$ would decrease particle sizes and increase the specific

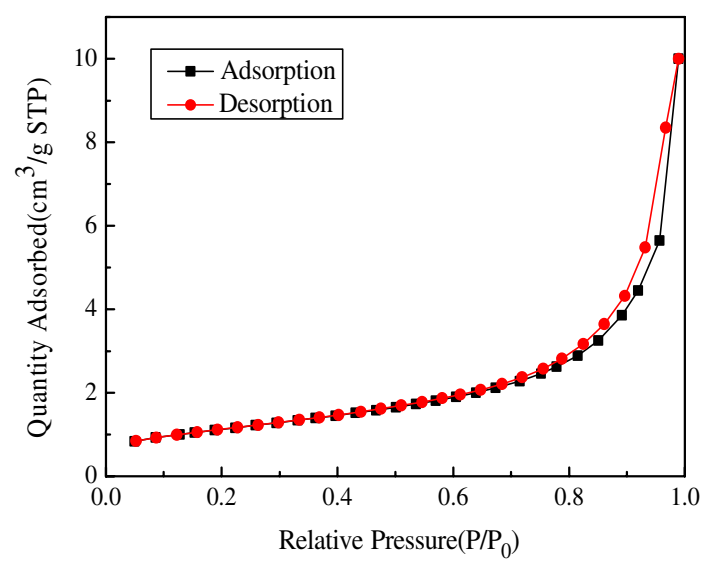

Fig. $6 \mathrm{~N}_{2}$ adsorption and desorption isotherms of $\mathrm{SA} / \mathrm{TiO}_{2}$

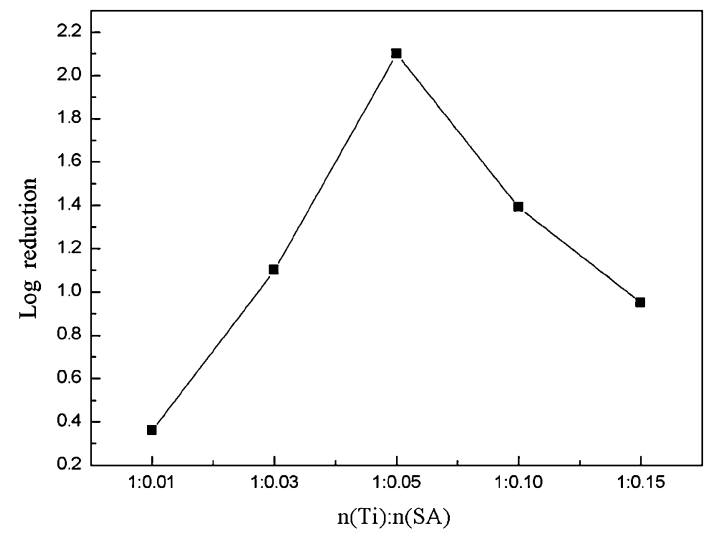

Fig. 7 Inactivation efficiency to E. coli $\left(10^{7} \mathrm{cfu} \mathrm{mL}^{-1}\right)$ with the asprepared samples $\left(0.1 \mathrm{~g} \mathrm{~L}^{-1}\right)$ under $\mathrm{UV}$ radiation

surface area after modified by SA, ultimately enlarging the contact area between the catalyst and the bacteria suspension. However, adding little SA could not greatly interact with the agglomerated $\mathrm{TiO}_{2}$, while excessive SA would coat on $\mathrm{TiO}_{2}$ surface failing to increase the dispersion of $\mathrm{TiO}_{2}$. Consequently, the optimum parameters of $n(\mathrm{Ti}): \mathrm{n}$ $(\mathrm{SA})=1: 0.05$ was determined.

\subsubsection{Effect of In Situ Water Content}

The ethanol volume was selected to represent the different in situ water content for convenience in this experiment, the ethanol and acetic acid volume were calculated by $\mathrm{V}\left(\mathrm{C}_{2} \mathrm{H}_{6} \mathrm{O}\right):\left(\mathrm{C}_{2} \mathrm{H}_{4} \mathrm{O}_{2}\right)=3: 2$. The curve in Fig. 8 showed the effect of the different in situ water content on the sterilization performance of the composite and the inactivation efficiency tendency of the composite was increasing firstly and then decreasing. When the ethanol volume was $60 \mathrm{~mL}$, the catalyst showed its excellent sterilization activity. The

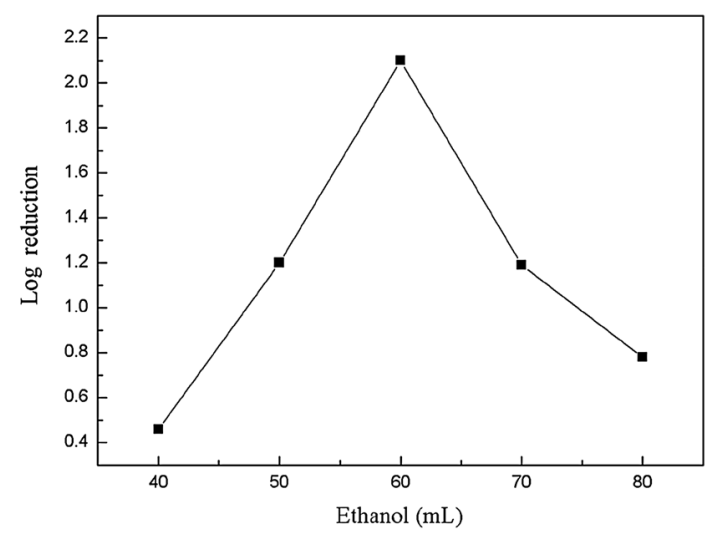

Fig. 8 Sterilization performance of $\mathrm{SA} / \mathrm{TiO}_{2}$ with different in situ water content 
interpretation for the tendency of inactivation performance was that Ti precursor failed to fully hydrolyze with little in situ water, and then the increasing of in situ water content accelerated the hydrolysis of tetrabutyl titanate, forming $\mathrm{TiO}_{2}$ particles with small sizes and large specific surface area [23], thus greatly enhancing the sterilization activity of the catalyst. However, when the in situ water content was over $60 \mathrm{~mL}$, due to the excessive water dilution, resulting in the viscosity of $\mathrm{TiO}_{2}$ sol, the crosslinking degree and polymerization degree of the polycondensate would significantly decrease, which hindered the crystal to the form complete structure in the subsequently solvothermal reaction [24]. Moreover, the reactants volume had greatly effect on the reactor filling degree and also affected the sterilization performance of the composite [25]. The low composite volume exhibited poor crystallinity for the low reactor filling degree at low reaction pressure. On the contrary, excessive volume composite showed too fast growth rate at high pressure. Therefore, the ethanol volume of $60 \mathrm{~mL}$ and the acetic acid volume of $40 \mathrm{~mL}$ were selected for further research.

\subsubsection{Effect of Hydrothermal Temperature}

Figure 9 presented the influence of the hydrothermal temperature on the photocatalytic sterilization activity of the catalyst. The results showed that the catalyst prepared at the hydrothermal temperature of $180{ }^{\circ} \mathrm{C}$ exhibited excellent sterilization activity. The precursor reaction was incomplete at low hydrothermal temperature, making the low growth rate, little size and poor crystallinity of the catalyst [26]. With the increasing of hydrothermal temperature, it provided more energy for the crystal growth and accelerated the phase transformation of $\mathrm{TiO}_{2}$ from rutile to anatase phase [27]. However, the fast supersaturation and crystallization rate might lead to the abnormal growth of the catalyst at too high hydrothermal reaction temperature

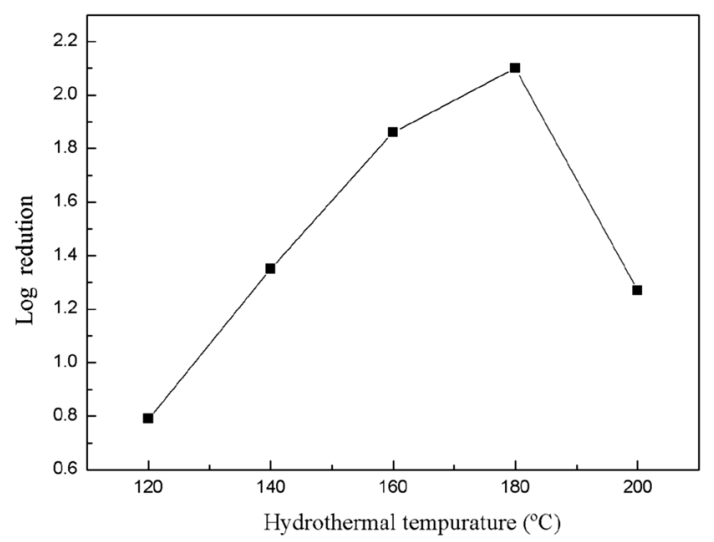

Fig. 9 Sterilization performance of $\mathrm{SA} / \mathrm{TiO}_{2}$ with different hydrothermal temperature
[28], and the synthesized powders were prone to agglomeration, decreasing the specific surface area of the crystals. More importantly, some SA would decompose, negatively affected its photocatalytic activity. Therefore, $180^{\circ} \mathrm{C}$ was chosen as the optimum hydrothermal reaction temperature in this experiment.

\subsubsection{Effect of Hydrothermal Time}

The sterilization activity of $\mathrm{SA} / \mathrm{TiO}_{2}$ at different hydrothermal time was investigated. As shown in Fig. 10, the inactivation efficiency of the composite increased remarkably with hydrothermal time increasing, and then gradually decreasing, moreover, the declining trend became obviously when the hydrothermal time was over $24 \mathrm{~h}$. It turned out that the composite obtained in a short time was noncrystalline with $\mathrm{TiO}_{2}$ particles obviously aggregation. Besides, less photogenerated electrons would be excited in the unit area of crystals, and the diffusion distance from the internal to surface would increase [29, 30], which decreased photocatalytic activity of the composite. As the hydrothermal time increasing, the catalyst continuously would grow having better crystallization and the crystal particles distributed more uniformly [31]. However, when the hydrothermal reaction time was over $12 \mathrm{~h}$, due to the gradually increasing of particles size, the defects on the crystal surface and the active sites decreased, resulting in the gradually decreasing of sterilization activity. Especially, when the hydrothermal reaction time was more than $24 \mathrm{~h}$, the sterilization effect of the catalyst obvious rapidly decreased, for the overgrown crystals mutual extrude and engulf forming the uneven sizes. Finally, the $\mathrm{SA} / \mathrm{TiO}_{2}$ synthesis at the hydrothermal condition of $12 \mathrm{~h}$ was selected for further experiments.

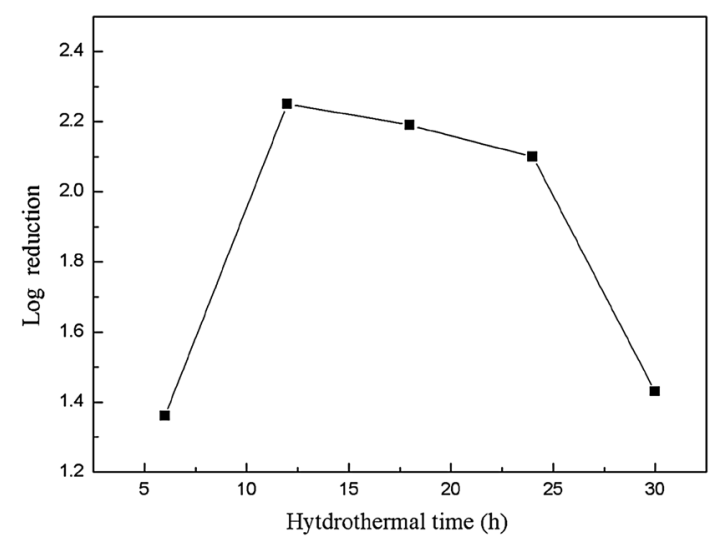

Fig. 10 Sterilization performance of $\mathrm{SA} / \mathrm{TiO}_{2}$ with different hydrothermal time 


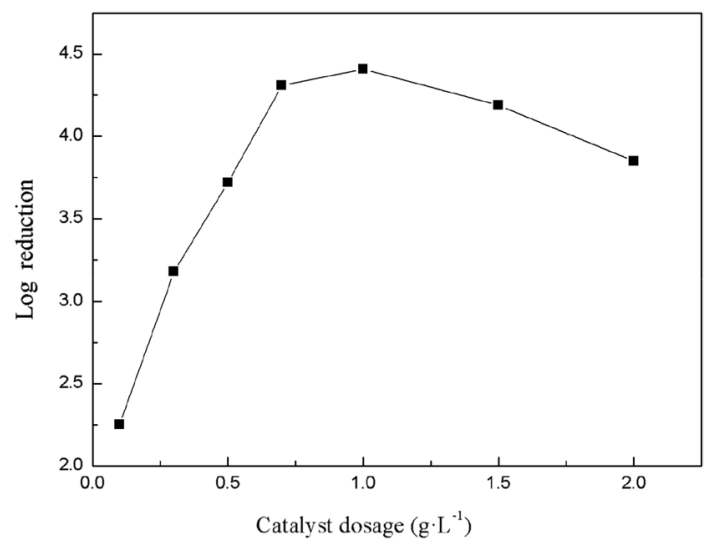

Fig. 11 Sterilization performance of $\mathrm{SA} / \mathrm{TiO}_{2}$ with different catalyst dosages

\subsection{The Influences of Different Environmental Factors on Sterilization Activity}

\subsubsection{Effect of Catalyst Dosages}

The effect of the different $\mathrm{SA} / \mathrm{TiO}_{2}$ dosages related to its cost on the inactivation efficiency against $E$. coli under UV light was shown in Fig. 11. The catalyst exhibited its best sterilization activity adding $\mathrm{SA} / \mathrm{TiO}_{2}$ to $1.0 \mathrm{~g} \mathrm{~L}^{-1}$. When the catalyst dosage was less than $1.0 \mathrm{~g} \mathrm{~L}^{-1}$, the log reduction increased rapidly due to the increasing contact area between the catalyst and bacteria, which created more active sites in the catalyst. Meanwhile, the ultraviolet utilization efficiency increased releasing more oxidizing groups [32], rapidly increasing the sterilization effect of the catalyst. Nevertheless, the $\log$ reduction would decrease when the catalyst dosage was more than $1.0 \mathrm{~g} \mathrm{~L}^{-1}$, for the catalyst concentration gradually increased and the bacteria suspension turbidity correspondingly increased, sheltering the light and reducing the transmittance of the solutions [33]. As a result, some catalysts away from the light source could not be stimulated by the UV light. On the other hand, the increasing of catalyst concentrations made some catalyst particles agglomerate each other [34], and the electron hole pairs were easy to recombine, which weakened the sterilization properties of the catalyst. The $\log$ reduction of E. coli reached $4.41 \log$ at the catalyst dosage of $1.0 \mathrm{~g} \mathrm{~L}^{-1}$, compared to $0.7 \mathrm{~g} \mathrm{~L}^{-1}$ only $0.1 \mathrm{log}$ higher. Therefore, the optimum economically dosage of catalyst was $0.7 \mathrm{~g} \mathrm{~L}^{-1}$ in this experiment.

\subsubsection{Effect of Irradiation Time}

The sterilization performance was strongly affected by irradiation time. The effects of different irradiation time on the sterilization properties of $\mathrm{SA} / \mathrm{TiO}_{2}$ were investigated under ultraviolet lamp irradiated for 10, 20, 30, 60, 90 and
120 min, respectively. The results were shown in Fig. 12, it depicted that the $\log$ reduction of $E$. coli increased rapidly from 1.45 to $3.41 \mathrm{log}$ at the irradiation time from 10 to $30 \mathrm{~min}$, however, it increased slowly in 30 to $60 \mathrm{~min}$. Irradiated by the continuous UV light, the increasing light quantum numbers provided more energy for the electronic excitation process of the catalyst, helpful for the oxidation groups to participate in the sterilization process. However, per unit volume of the catalyst content in the bacteria suspensions was fixed so that the formation efficiency of the electron-hole pairs gradually decreased when the radiation time reached $30 \mathrm{~min}$. The increasing tendency of the log reduction of $E$. coli was quite slowly when the radiation time exceeded $60 \mathrm{~min}$, due to the limitation of bacteria numbers. In short, the inactivation efficiency was relatively efficient when the radiation time was $60 \mathrm{~min}$ and the catalyst showed excellent sterilization performance at this condition.

\subsubsection{Effect of Humic Acid}

Various dissolved organic matter (DOM) in aquatic environment had a great effect on the sterilization performance of materials. As a representative compound of DOM, humic acid (HA) had been widely used to evaluate the effect of natural organic matter on the environmental geochemical processes [35]. HA was a major component of humic substances coming from the decomposition of plants and animal [36], and it belonged to a kind of chemically heterogeneous compound containing abundant functional groups such as phenolic, hydroxyl, and carboxyl. Some research showed that HA could be absorbed on the nanomaterials surface, and the functional groups of HA such as carboxylate and phenolic had a strong complexation effect probably affecting the photocatalytic performance of the nanomaterials [37]. Therefore, the disinfection of pathogens in water might be affected by HA and it was still urgent to investigate the effect of HA on SA/

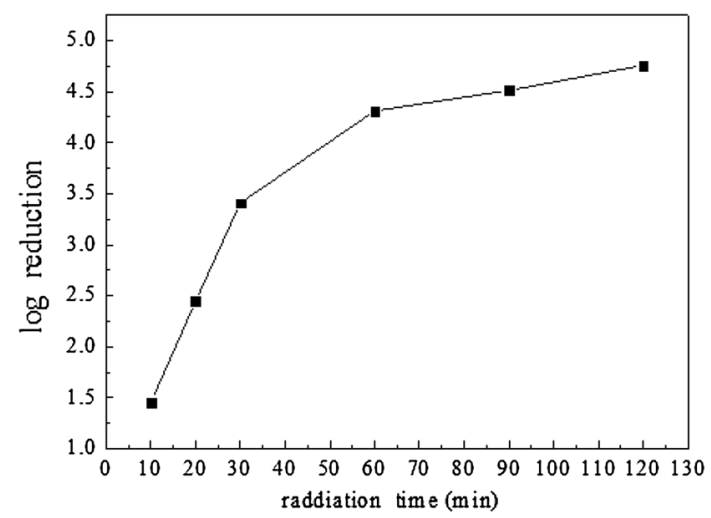

Fig. 12 Sterilization performance of $\mathrm{SA} / \mathrm{TiO}_{2}$ with different irradiation time 


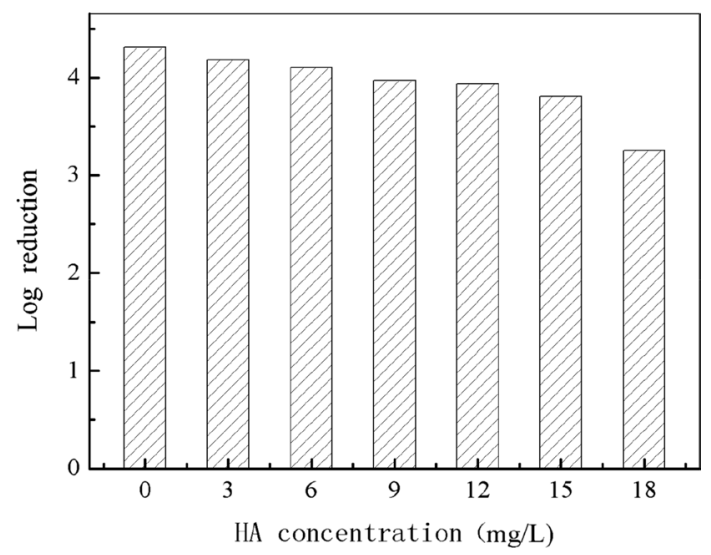

Fig. 13 Effect of HA concentration on sterilization properties of composite

$\mathrm{TiO}_{2}$. The HA concentration in the typical surface water was about $10 \mathrm{mg} \mathrm{L}^{-1}$ [38]. In this work, the effect of different $\mathrm{HA}$ concentrations in the range of $3-18 \mathrm{mg} \mathrm{L}^{-1}$ on the disinfection performance of $E$. coli cells were investigated. As shown in Fig. 13, the increasing of HA concentrations would decrease the disinfection efficiency and the decreasing tendency became obviously when the concentration reached $18 \mathrm{mg} \mathrm{L}^{-1}$. The sterilization performance of the composite was slightly affected by the concentrations of HA which generally below $10 \mathrm{mg} \mathrm{L}^{-1}$ in actual water sources.

\section{Conclusions}

The photocatalyst sorbic acid (SA)/titanium dioxide $\left(\mathrm{TiO}_{2}\right)$ was prepared by sol-gel method and characterized by a series of analysis techniques. The results indicated that the composite presented regularly spherical particles with the size of $50 \mathrm{~nm}$ and excellent dispersion. $\mathrm{TiO}_{2}$ existed as pure anatase phase in the composite and $\mathrm{SA}$ was grafted on $\mathrm{TiO}_{2}$ surface by -COOTi forming mesoporous structure with the specific surface area of $90.3 \mathrm{~m}^{2} \mathrm{~g}^{-1}$. The addition of SA made the band gap of $\mathrm{TiO}_{2}$ slightly increased from 3.03 to $3.35 \mathrm{eV}$, implying the composite showed strongly response to the UV light. The optimum preparation parameters of the catalyst were $n(\mathrm{Ti}): \mathrm{n}(\mathrm{SA})=1: 0.05,60 \mathrm{~mL}$ ethanol and $40 \mathrm{~mL}$ glacial acetic acid at the hydrothermal temperature of $180{ }^{\circ} \mathrm{C}$ for $12 \mathrm{~h}$. The composite $\left(0.7 \mathrm{~g} \mathrm{~L}^{-1}\right)$ showed excellent photocatalytic sterilization performance, which could reach the $\log$ reduction of $E$. coli to $4.31 \log$ under the UV light irradiation for $60 \mathrm{~min}$. In a word, $\mathrm{SA} / \mathrm{TiO}_{2}$ provided a new path to hinder the agglomeration of $\mathrm{TiO}_{2}$ nanoparticles by enhancing $\mathrm{TiO}_{2}$ surface acidity, thus achieving a safe and effective drinking water disinfection method.

\section{References}

1. A. Boretti, L. Rosa, Reassessing the projections of the World Water Development Report. npj Clean Water 2(1), 1-6 (2019)

2. T. Matsunaga, R. Tomoda, T. Nakajima et al., Photoelectrochemical sterilization of microbial cells by semiconductor powders. FEMS Microbiol. Lett. 29(1), 211-214 (1985)

3. J. Du, X. Lai, N. Yang et al., Hierarchically ordered macromesoporous $\mathrm{TiO}_{2}-$ graphene composite films: improved mass transfer, reduced charge recombination, and their enhanced photocatalytic activities. ACS Nano 5(1), 590-596 (2010)

4. M.C. Blount, D.H. Kim, J.L. Falconer, Transparent thin-film $\mathrm{TiO}_{2}$ photocatalysts with high activity. Environ. Sci. Technol. 35(14), 2988-2994 (2001)

5. P. Muranyi, C. Schraml, J. Wunderlich, Antimicrobial efficiency of titanium dioxide-coated surfaces. J. Appl. Microbiol. 108(6), 1966-1973 (2010)

6. K. Shiraishi, H. Koseki, T. Tsurumoto et al., Antibacterial metal implant with a TiO2-conferred photocatalytic bactericidal effect againstStaphylococcus aureus. Surf. Interface Anal. 41(1), 17-22 (2009)

7. J.H. Lee, M. Kang, S. Choung et al., The preparation of $\mathrm{TiO} 2$ nanometer photocatalyst film by a hydrothermal method and its sterilization performance for Giardia lamblia. Water Res. 38(3), 713-719 (2004)

8. Q. Zhang, L. Li, Y. Liu et al., Grafting dynamics, structures and properties of nano $\mathrm{TiO}_{2}$-SA photocatalytic materials. Acta Phys. Chim. Sin. 31(6), 1015-1024 (2015)

9. N.N. Ilkhechi, M.R. Akbarpour, R. Yavari et al., Sn4+ and La3+ co doped $\mathrm{TiO} 2$ nanoparticles and their optical, photocatalytic and antibacterial properties under visible light. J. Mater. Sci. 28(22), 16658-16664 (2017)

10. K. Tahir, A. Ahmad, B. Li et al., Preparation, characterization and an efficient photocatalytic activity of $\mathrm{Au} / \mathrm{TiO}_{2}$ nanocomposite prepared by green deposition method. Mater. Lett. 178, 56-59 (2016)

11. B. Liu, L. Mu, B. Han et al., Fabrication of $\mathrm{TiO}_{2} / \mathrm{Ag}_{2} \mathrm{O}$ heterostructure with enhanced photocatalytic and antibacterial activities under visible light irradiation. Appl. Surf. Sci. 396, 1596-1603 (2017)

12. A. Athanasiou, A. Mitsionis, T. Vaimakis et al., A novel route for the production of $\mathrm{TiO} 2$ photocatalysts with low energy gap, via Triton-X and oleic acid surfactants. Appl. Surf. Sci. 319, 143-150 (2014)

13. H. Li, B. Liu, S. Yin et al., Visible light-driven photocatalytic activity of oleic acid-coated $\mathrm{TiO}_{2}$ nanoparticles synthesized from absolute ethanol solution. Nanoscale Res Lett 10(1), 415 (2015)

14. W.Y. Su, Y.L. Chen, X.Z. Fu et al., Acid strength and photocatalytic activity of SO42-/TiO2 solid acid catalyst. Chin. J. Catal. 22(2), 175-176 (2001)

15. M.F. Nsib, A. Maayoufi, N. Moussa et al., TiO2 modified by salicylic acid as a photocatalyst for the degradation of monochlorobenzene via Pickering emulsion way. J. Photochem. Photobiol. A 251, 10-17 (2013)

16. EFSA Panel on Additives and Products or Substances used in Animal Feed (FEEDAP), Scientific Opinion on the safety and efficacy of sorbic acid and potassium sorbate when used as technological additives for all animal species based on two dossiers from Nutrinova Nutrition Specialties \& Food Ingredients $\mathrm{GmbH}$. EFSA J. 13(9), 4239 (2015)

17. R. Wang, Development and use of sorbic acid. Beverage Ind. 10, 5-7 (2007)

18. K. Lonsdale, J.M. Robertson, I. Woodward, Structure and molecular anisotropy of sorbic acid, $\mathrm{CH} 3 . \mathrm{CH}: \mathrm{CH}$. $\mathrm{CH}$ : $\mathrm{CH} \mathrm{COOH}$. Proc. R. Soc. Lond. A 178(972), 43-52 (1941) 
19. A. Garcia-Ac, R. Broséus, S. Vincent et al., Oxidation kinetics of cyclophosphamide and methotrexate by ozone in drinking water. Chemosphere 79(11), 1056-1063 (2010)

20. G. Madras, B.J. Mccoy, A. Navrotsky, Kinetic model for $\mathrm{TiO}_{2}$ polymorphic transformation from anatase to rutile. J. Am. Ceram. Soc. 90(1), 250-255 (2007)

21. X. Lin, J. Li, S. Ma et al., Toxicity of $\mathrm{TiO}_{2}$ nanoparticles to Escherichia coli: effects of particle size, crystal phase and water chemistry. PLoS ONE 9(10), e110247 (2014)

22. T. Rajh, A.E. Ostafin, O.I. Micic et al., Surface modification of small particle $\mathrm{TiO}_{2}$ colloids with cysteine for enhanced photochemical reduction: an EPR study. J. Phys. Chem. 100(11), 45384545 (1996)

23. S. Valencia, X. Vargas, L. Rios et al., Sol-gel and low-temperature solvothermal synthesis of photoactive nano-titanium dioxide. J. Photochem. Photobiol. A 251, 175-181 (2013)

24. Z. Shi, P. Tian, Y. Kang, Study on the mechanism of nano TiO2 gel prepared by sol gel method. J. Shenyang Norm. Univ. 3, 412 $415(2010)$

25. Y. Wang, C. Liu, Y. Bo, Thermodynamic properties of high temperature and high pressure ionic aqueous solvent in solvothermal reactor. J. Chem. Ind. Eng. 08, 1856-1864 (2006)

26. P. Zhao, T. Huang, K. Huang, Fabrication of indium sulfide hollow spheres and their conversion to indium oxide hollow spheres consisting of multipore nanoflakes. J. Phys. Chem. C 111(35), 12890-12897 (2007)

27. T. Suwannaruang, K.K.P. Rivera, A. Neramittagapong et al., Effects of hydrothermal temperature and time on uncalcined $\mathrm{TiO}_{2}$ synthesis for reactive red 120 photocatalytic degradation. Surf. Coat. Technol. 271, 192-200 (2015)

28. Q. Wei, Y. Chen, Solvothermal synthesis of titanium dioxide nanowires by one-step method and their photocatalytic properties. Chem. J. Chin. Univ. 11, 2483-2489 (2011)

29. J. Yu, G. Wang, B. Cheng et al., Effects of hydrothermal temperature and time on the photocatalytic activity and microstructures of bimodal mesoporous TiO2 powders. Appl. Catal. B 69(3-4), 171-180 (2007)

30. A. Khataee, M. Sheydaei, A. Hassani et al., Sonocatalytic removal of an organic dye using $\mathrm{TiO} 2 /$ Montmorillonite nanocomposite. Ultrason. Sonochem. 22, 404-411 (2015)
31. Y.A. Shaban, M.A. El Sayed, A.A. El Maradny et al., Photocatalytic degradation of phenol in natural seawater using visible light active carbon modified (CM)-n- $\mathrm{TiO}_{2}$ nanoparticles under UV light and natural sunlight illuminations. Chemosphere 91(3), 307-313 (2013)

32. Y. Li, Q. Zhao, Y. Ge, Catalytic ozonation of salicylic acid in aqueous solutions by metal oxide supported catalysts. J. Chem. Eng. Chin. Univ. 30(2), 446-453 (2016)

33. L.K. Adams, D.Y. Lyon, P.J.J. Alvarez, Comparative eco-toxicity of nanoscale $\mathrm{TiO}_{2}, \mathrm{SiO}_{2}$, and $\mathrm{ZnO}$ water suspensions. Water Res. 40(19), 3527-3532 (2006)

34. Q. Rahman, M. Lohani, E. Dopp et al., Evidence that ultrafine titanium dioxide induces micronuclei and apoptosis in Syrian hamster embryo fibroblasts. Environ. Health Perspect. 110(8), 797-800 (2002)

35. M. Erhayem, M. Sohn, Effect of humic acid source on humic acid adsorption onto titanium dioxide nanoparticles. Sci. Total Environ. 470-471, 92-98 (2014)

36. M. Mori, T. Sugita, A. Mase, T. Funatogawa, M. Kikuchi, K. Aizawa, S. Kato, Y. Saito, T. Ito, H. Itabashi, Photodecomposition of humic acid and natural organic matter in swamp water using a $\mathrm{TiO}_{2}$-coated ceramic foam filter: potential for the formation of disinfection byproducts. Chemosphere 90(4), 1359-1365 (2013)

37. J. Li, S. Zhang, C. Chen, G. Zhao, X. Yang, J. Li, X. Wang, Removal of $\mathrm{Cu}$ (II) and fulvic acid by graphene oxide nanosheets decorated with $\mathrm{Fe} 3 \mathrm{O} 4$ nanoparticles. ACS Appl. Mater. Interfaces. 4(9), 4991-5000 (2012)

38. A.K. Camper, Involvement of humic substances in regrowth. Int. J. Food Microbiol. 92(3), 355-364 (2004)

Publisher's Note Springer Nature remains neutral with regard to jurisdictional claims in published maps and institutional affiliations. 